\title{
The Study on the TCM Translation under Big Data
}

\author{
Zixun Yu \\ Changchun University of Traditional Chinese Medicine, Changchun, Jilin, China, 130000
}

Keywords: big data era; TCM translation; the analysis of impact factor; promotion strategy interpretation

\begin{abstract}
The arrival of the big data era has put forward new requirements for the teaching of English translation of traditional Chinese medicine, and has provided a rare opportunity for the development of English translation teaching. This paper, based on the analysis big data era, on the basis of the connotation of teaching methods, analyzes subjective and objective factors affecting the English translation of traditional Chinese medicine teaching methods combining with the era of big data, and discusses how to improve the English translation of traditional Chinese medicine teaching methods in the big data era.
\end{abstract}

\section{Introduction}

English translation teaching of Traditional Chinese medicine is the most important in English teaching of Chinese medicine. Translation teaching is not only the way to consolidate the basic knowledge of English, but also the necessary means to cultivate Chinese doctors ' English ability. Especially in the background big data era, it is of great significance to explore the relevant problems of Chinese medicine English translation for expanding the teaching reform of TCM and to explore the concrete teaching reform practice. Combining with the teaching work of Chinese traditional English translation practice, the article explains and explains in detail the core problems of Chinese traditional English translation teaching in the age of large data.

\section{The Big Data Era and the Teaching Methods of Translation}

The information technology participates in the English teaching practice degree to deepen; the big data era arrival all has provided the rare opportunity for the Chinese Medicine English translation teaching development. Not only it caused the society to translate talented person's demand to obtain grew fast, moreover also to translated in the foundation in the increase which the talented person needed, to translated talented person's practice ability to set a higher request .In order to explore the best teaching strategies in English translation teaching of Chinese medicine, it is necessary to analyze the problems of English translation methods, The analysis of the English translation of the Chinese teaching method on the premise of the two core concepts related to the definition and description.

\subsection{Big data era}

Big data mainly refers to the size beyond the traditional database software tools storage, capture, analysis and management capabilities of the data group. Based on the application pattern and data processing of cloud computing, the knowledge service ability and intelligence resources can be formed by cross multiplexing and integrated data sharing. [1]. This means that the so-called large data is a resource, and the formation of this resource is closely related to the formation of the data group. The digital age is a relative concept, with the opposite term is "small data Era". The symbol of the small data age is the "database" software, and the symbol of the big data age is the data integration with "cloud" as the symbol.

\subsection{The teaching method of translation}

How to understand the method of translation teaching depends on how to understand the core 
term of "method". In teaching practice, regarding "method" the understanding, the different researcher has the different understanding. First, the "method" should be a certain period of time in the teaching practice received the specific effect. In the word "method", the "time" in front is the meaning of "specific time", which limits the specific time that the "effect" behind it produces. Secondly, in the teaching practice, "the method" can also understand "the actual effect", namely the objective teaching effect which the concrete teaching practice activity receives. In the future, a kind of understanding as the standard, the English translation of traditional Chinese teaching methods for the relevant interpretation and explanation. The teaching method of English translation of Traditional Chinese medicine refers to the concrete teaching effect received by the practice of English translation teaching." The study of the teaching methods of Chinese Medicine translation in the age of large data" is to discuss the concrete effect of the practice of "teaching Chinese Medicine English translation under the background of large data".

\section{Influencing Factors of Methods}

\subsection{The matching of teaching background and teaching strategy.}

The most important factors that affect the teaching methods of English translation of Chinese Medicine are the teaching strategies of English translation of Chinese Medicine and the teaching background of Chinese medicine English translation. That is, the teaching strategies of Chinese Medicine English translation and the Big Data age match each other. In the traditional Chinese medicine English translation teaching practice, the translation teaching strategy is translating the personnel training with the tradition the demand to adapt mutually. However, as the data age, a community for the English translation of the needs of the people and the emergence of new changes. It not only requires the translator to master the corresponding English knowledge, understand the relevant translation skills, but also need the translator with the relevant information technology, Through the background of the large data age, realize the influence of translation teaching to many learners. In other words, if a translation teacher can use the data provided by the era of information technology for teaching and learning practices to maximize the impact of his translation teaching practices will be even more the teaching effectiveness. Therefore, the matching of teaching strategies in the large data age is an important factor affecting the size of the teaching effect.

\subsection{Teaching content and students ' learning needs.}

Translation teaching content and students' learning needs mutual matching is another basic factors affecting the teaching effect. In the traditional teaching practice of English translation, the classroom teachers only need to teach the students the knowledge and skills of translation. But facing big data time arrival, not only translates the content has had the change which keeps pace with the times, moreover the translation skill has also had the corresponding vicissitude in the change which this kind kept pace with the times. Therefore, teachers also need to combine specific teaching requirements, choose some new translation content as a supplement to teaching, so as to improve the students ' learning effect.

\subsection{The gap between curriculum system and teaching demand.}

The arrival of the large data age not only puts forward new requirements for teaching strategies and teaching contents, but also puts forward new reform opinions for the construction of translation curriculum system. As we all know, the construction of translation curriculum system is not only the necessary strategy to adapt to the development of the Times, but also the key to the reform of traditional translation teaching. In particular, in the face of the big data era to the English translation talents of the new requirements. Only the reform of English translation teaching from the level of curriculum is the scientific choice to improve the teaching effect of teachers. This rare precious lesson, because the teacher is busy to complete the so-called teaching tasks and ignore the students ' interest in the translation of the training, so that the long-term teaching effect can not be improved. 


\section{Promotion Strategies of Methods}

Analyze the impact of the era of big data practitioners of Chinese medicine English teaching methods of subjective and objective factors, the purpose of which is to develop appropriate strategies to enhance the promotion of big data era the Chinese English translation teaching practice at a rapid pace. Based on the above analysis, promotion strategy can be simply summed up as: Update the curriculum, educational reform, and extensive coaching skills.

\subsection{Update curriculum system.}

Updated curriculum system is the key to improve translation teaching methods, no matter how excellent teaching skills, classroom teachers have without curriculum system updates can make teaching ability objectively cast in concrete teaching practice.

\subsection{Reform education idea.}

The education idea including three stratification plane education ideas, namely teaches classes teacher's education idea, superintendent's education idea and learner's education idea. Only the three-level concepts have been keeping up with the times, it could facilitate the translation of teaching effectiveness. Otherwise, any more than one level of updating concept, its effect on translation of traditional Chinese medicine teaching effect is limited. In other words, only the impact of the three levels in harmony in specific translation teaching practice, the effect of translation teaching, can obtain the huge promotion.

\subsection{Rich coaching skills.}

If the doctor of traditional Chinese medicine English teaching managers from a macro level affect specific translation teaching, the teacher is from micro level to make this kind of influence to teaching reality. Rich teacher's teaching skill, not only can make it more adaptable to the education background of the era of big data, and it also can improve the teaching effect. From another aspect analysis, the teacher is the subject of translation teaching activity, he controls the specific development of teaching practice, the teaching ability is the core factor of influence the translation teaching method. Therefore, teachers should be guided by its wealth of coaching skills as a breakthrough point so as to enhance the translation of limitation for teaching and learning.

\section{The Suggestion of Innovating the Teaching Mode of Chinese Medicine English Translation in Big Data Era}

\subsection{The reform of the translation process}

The large data age has given different meanings to Chinese medicine English translation, and the process of translation is no longer the interaction between the simple author, the text and the reader, but the complex and changeable process, the translator and the reader's identity constantly changing, and even converting to each other. The translation process in the large data age can be an individual behavior or a collective action, a one-time action, or a process of continuous revision and continuous improvement. The process of translation can be either the expression of personal thoughts or emotions, or the feedback of the expression of other people's thoughts and emotions. This requires Chinese traditional English translation teachers to design teaching programs in a multidimensional way. For example, teachers can organize students to choose materials for translation, and then recommend the translation to other students, using a variety of intelligent search or evaluation tools to improve the quality of the translation. The student may publish them in the network platform, but also may act according to other people appraisal to carry on the revision. In this process, translates from the teaching goal turns one kind of natural human relations behavior.

\subsection{The reform of translation evaluation.}

The teaching of translation in large data age is inseparable from information technology. The collection of data, the presentation of various teaching materials, the organization of classroom 
teaching activities, the submission of assignments, revision and review, and the interaction between teachers and students all require the support of network teaching platform and job evaluation system. The teaching platform of the large data age can integrate different network application systems and functions, integrate the teaching resources inside and outside the school, and embed the teaching platform of the school with the independent online application, such as online dictionary, online grammar Help and online corpus retrieval. Large data technology can be based on students online text analysis of the students at present in terms of vocabulary, syntax, text and other aspects of the level, summed up their language ability in different dimensions of input and learning effects, and accordingly recommend targeted recommendations.

\subsection{Improve the teachers ' application ability of information technology.}

Large data age provides a lot of technology and tools for teaching, different technologies have different characteristics and functions, which require teachers to study hard and constantly adjust their functions in teaching. Teachers are no longer the instructors of knowledge and skills, but the organizers and participants of teaching activities. Technicians should provide necessary information and consultation for teachers, and managers should organize necessary training and learning to help teachers adapt to the transformation of functions brought by new technology. The successful application of information technology in the teaching of English translation of Traditional Chinese medicine requires the cross-border cooperation between teachers and information workers.

\section{Conclusion}

The arrival of the big data era not only puts forward new requirements for the teaching of English translation of Chinese Medicine, but also provides a rare opportunity for the development of English translation teaching. Every teacher of Chinese medicine translation teaching should pay attention to the relevant problems in the teaching methods of Chinese Medicine English translation in the age of big data, so as to improve the quality of English translation teaching of Traditional Chinese medicine.

\section{Acknowledgement}

The 13th Five-year Social Science Project of Jilin Education Department, Topic Name: Big-data-based English Translation of TCM; A Practice and Study; Topic Number: JJKH20170756SK

\section{References}

[1] Yang Jie. A study of college English translation in the age big data [J]. English Square, 2015 (09).

[2] Wang Haixiao. Reform of college English writing teaching in the age of big data [J]. Modern distance education research, 2014 (03).

[3] Shen Hongwei, Jiang Haixia. Study on the Independent development of college English teachers in the era of big data [J]. Journal of Changchun University, 2015 (02). 